\title{
Wave propagation and reflection in the aorta and implications of the aortic Windkessel
}

\author{
John V. Tyberg@ \\ Emeritus Professor of Cardiac Sciences and Physiology/Pharmacology, Libin Cardiovascular Institute, Cumming School of \\ Medicine, University of Calgary, Calgary, Alberta T2N 4N1, Canada
}

*Correspondence: John V. Tyberg, Department of Cardiac Sciences and Physiology/Pharmacology, Libin Cardiovascular Institute, Cumming School of Medicine, University of Calgary, Calgary, AlbertaT3S, Canada. jtyberg@ucalgary.ca

Academic Editor: Kathleen Morgan, Boston University, USA

Received: March 30, 2021 Accepted: April 25, 2021 Published: June 30, 2021

Cite this article: Tyberg JV. Wave propagation and reflection in the aorta and implications of the aortic windkessel. Explor Med. 2021;2:198-207. https://doi.org/10.37349/emed.2021.00042

\begin{abstract}
Some have said that it is inappropriate and perhaps impossible to consider wave and Windkessel phenomena simultaneously. For 50 years, arterial hemodynamics has been dominated by the frequency-domain "impedance analysis" in which it was assumed that all variations in aortic pressure and flow were caused only by forward- and backward-going waves. This paper is a review of the results of incorporating the effects of Frank's Windkessel. We have taken the view that measured aortic pressure is the sum of a Windkessel component and forward-going and backward-going wave components. When the Windkessel component is initially subtracted out, the pattern of propagation and reflection of wave components becomes clear. Furthermore, this analysis obviates the implications of impedance analysis that have not been explained satisfactorily.
\end{abstract}

\section{Keywords}

Hemodynamics, aorta, waves, Windkessel

\section{Introduction}

The "classical" approach to aortic wave propagation and reflection is based upon Westerhof's 1972 paper [1]. It was assumed that all variations in aortic pressure $(P)$ and velocity ( $U$, flow) could be explained by the summation of forward- and backward-going waves. A wave has been defined by Lighthill as a disturbance that changes both pressure and velocity when it passes $[2,3]$.

Having come from a background of using wave intensity (WI) analysis (WIA) [4] in which WI is calculated from the change in pressure $(\Delta P)$ and the change in velocity $(\Delta U)$, we concluded that $\Delta P$ might not be entirely due to the passage of waves but could be related to the elastance of the aorta, if the volume of the aorta changes [5] (Elastance was assumed to be constant and this assumption was supported by unpublished observations). Thus, we suggested that aortic pressure should be considered as the sum of pressures: a 
Windkessel pressure in addition to the pressures due to the passage of waves. (In our later publications, we substituted "reservoir" for Windkessel.)

\section{Defining the Aortic Windkessel}

As Frank [6] proposed, we consider the Windkessel to be a hydraulic integrator, the change of Windkessel pressure $\left(\Delta P_{\mathrm{wk}}\right)$ in which is directly related to its change in Windkessel volume $\left(\Delta V_{\mathrm{wk}}\right)$ and inversely related to its compliance. The rate of change in $V_{\mathrm{wk}}$ is simply the difference between the inflow from the left ventricle (LV) that can be measured and outflow to the periphery that can be calculated.

These principles are best explained in reference to Figure 1. As shown in the top panel, during diastole aortic pressure $\left(P_{\mathrm{AO}}\right)$ decreases exponentially with a time constant, $\tau=$ resistance and compliance (RC) (a limitation of the approach is that the exponential decay cannot be demonstrated if the heart rate is too high). This implies that $P_{\mathrm{Ao}}$ will fall to an asymptotic level, asymptotic pressure $\left(P_{\infty}\right)$, after infinite time, which we found to be 30 to $40 \mathrm{mmHg}$ in our anesthetized dogs [7]. The value of $P_{\mathrm{wk}}$ during the remainder of the cardiac cycle is calculated using Equation 3 in Wang's paper [8], which expresses $P_{\mathrm{wk}}$ as a function of $P_{\mathrm{Ao}}$ at the beginning of ejection, of aortic inflow, and of aortic compliance. In the proximal aorta, velocity is zero during diastole while aortic pressure decreases from the end-systolic value to the end-diastolic value. When the heart rate is normally low, we assumed that there were no waves during the latter part of diastole and that the change in diastolic pressure represented the exponential "bleeding off" of a hydraulic capacitor.

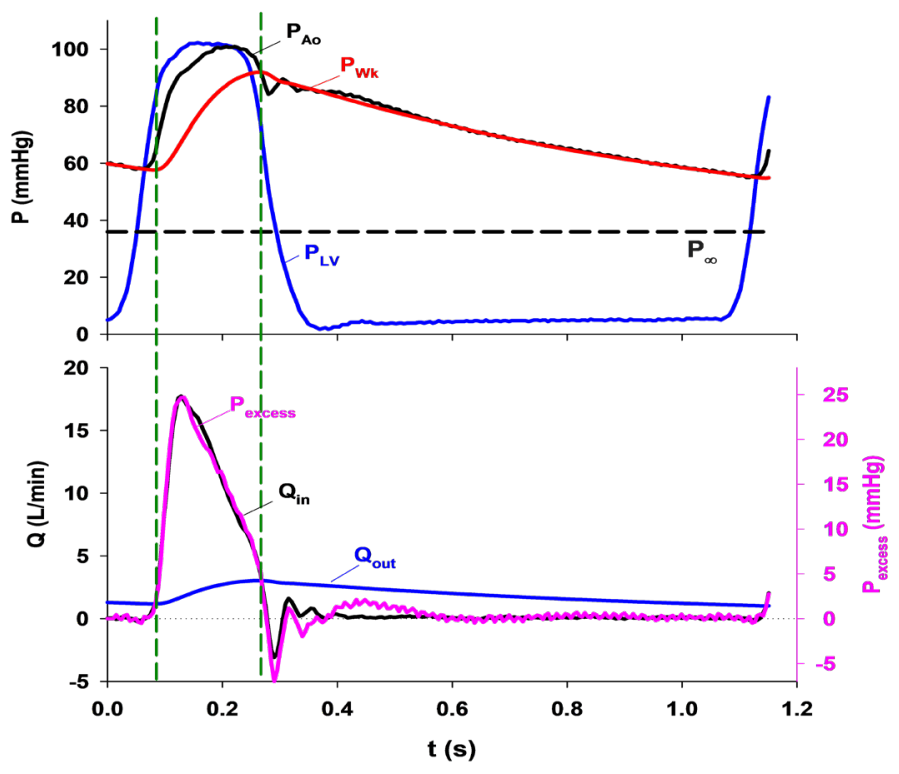

Figure 1. Upper panel: typical aortic root pressure $\left(P_{\text {Ag }}\right.$, black), left ventricular pressure $\left(P_{\mathrm{LV}}\right.$, blue), calculated Windkessel pressure $\left(P_{\mathrm{wk}}\right.$, red $)$ and the asymptotic pressure $\left(P_{\infty}\right.$, black dashed line). Lower panel: excess pressure $\left(P_{\text {excess }}\right.$, pink) calculated by subtracting PWk from PAo and aortic inflow $\left(Q_{i n}\right.$, black) plotted against time with the scales adjusted so that their peak values coincide. Note that they are almost identical in contour. The Windkessel charges when inflow is greater than outflow and vice versa. Two vertical dashed lines mark the instants when $Q_{\text {in }}$ equals outflow ( $Q_{\text {out }}$, blue) and, therefore, $P_{w k}$ does not change [5]

Note. Reprinted with permission from "Time-domain representation of ventricular-arterial coupling as a windkessel and wave system" by Wang JJ, O'Brien AB, Shrive NG, Parker KH, Tyberg JV. Am J Physiol Heart Circ Physiol. 2003; 284:H1358-68 (https:// doi.org/10.1152/ajpheart.00175.2002). (C) The American Physiological Society.

We measured aortic inflow and calculated aortic outflow, which is proportional to the difference between $P_{\mathrm{wk}}$ and $P_{\infty}$ (see the bottom panel). Since integrated outflow must equal integrated inflow, it becomes possible to calculate outflow. Then, by comparing inflow and outflow, the contour of $P_{\mathrm{wk}}$ becomes understandable. $P_{\mathrm{wk}}$ is the pressure of a volume integrator. When aortic inflow exceeds outflow (i.e., during most of systolic ejection) Windkessel volume and $P_{\mathrm{wk}}$ increase and when aortic outflow exceeds inflow (during the remainder of the cycle) Windkessel volume and $P_{\mathrm{wk}}$ decrease.

Parker [9] defined excess pressure $\left(P_{\text {excess }}\right)$ as the difference between measured $P_{\mathrm{Ao}}$ and $P_{\mathrm{wk}}$. Thus, we arbitrarily scaled that pressure and plotted it on the bottom panel of Figure 1. Remarkably, we found it to be 
precisely proportional to aortic inflow. The ratio of a pressure difference to a flow has units of resistance. We calculated this ratio and found that it was equal to so-called characteristic impedance (in their earlier paper, Westerhof et al. [10] used "resistance" rather than "impedance"). Thus, we interpreted this ratio to be the property of a proximal resistance functionally separating the LV from the Windkessel, as shown in Figure 2 and discussed in detail elsewhere [11,12].

$P_{\mathrm{wk}}$ is wave-like in that it, too, is a propagated disturbance [3], as we described [12] (note Animation 3 particularly).

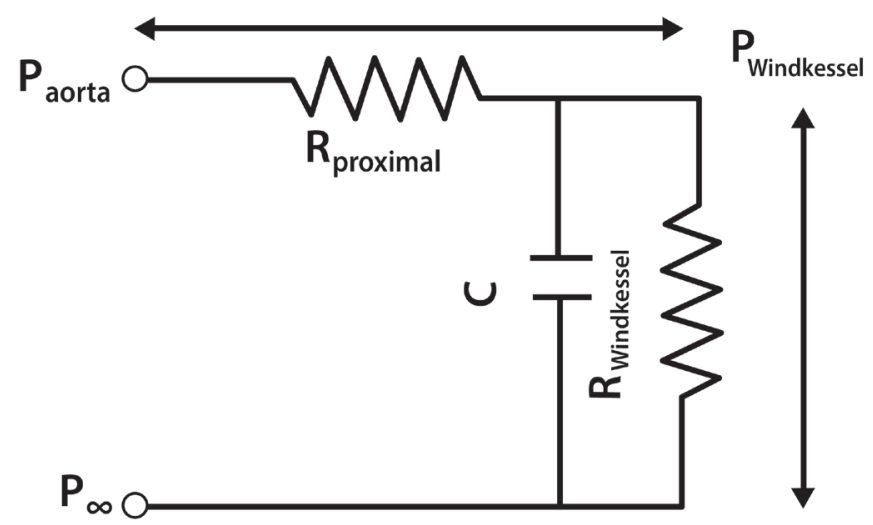

Figure 2. An electrical analogue of the 3-element Windkessel (reservoir). The pressure difference across the whole circuit is equal to the difference between $P_{\text {aorta }}$ and $P_{\infty}$. $R_{\text {proximal }}$ is a resistance interposed between the LV and the Windkessel and is equivalent to characteristic impedance. $P_{\text {wave }}$ is generated by the passage of $Q_{\text {in }}$ through $R_{\text {proximal }}$ and is equal to the pressure difference across it. $\mathrm{C}$ is the compliance and $R_{\text {windkessel }}$ is the resistance of the reservoir (filter). The pressure difference specifically due to the Windkessel is equal to $\left(P_{\text {Windkesse }}-P_{\infty}\right)[11]$

Note. Reprinted with permission from "The reservoir-wave paradigm: potential implications for hypertension" by Tyberg JV, Shrive NG, Bouwmeester JC, Parker KH, Wang Jr J. Curr Hypertens 2008;4:203-13. (https://doi.org/10.2174/157340208785132572). () EUREKA SCIENCE.

Parker [9] defined $P_{\text {excess }}$ but $P_{\text {excess }}$ can be broken down further into that due to forward-going waves $\left(P_{\text {excesst }}\right)$ and that due to backward-going waves $\left(P_{\text {excess }}\right)$. This is illustrated in Figure 3. $P_{\text {Ao }}$ (black) recorded from the renal region in a particular experiment is the complex summation of $P_{\mathrm{wk}}$ and the pressures due to forward- (red) and backward-going waves (blue).

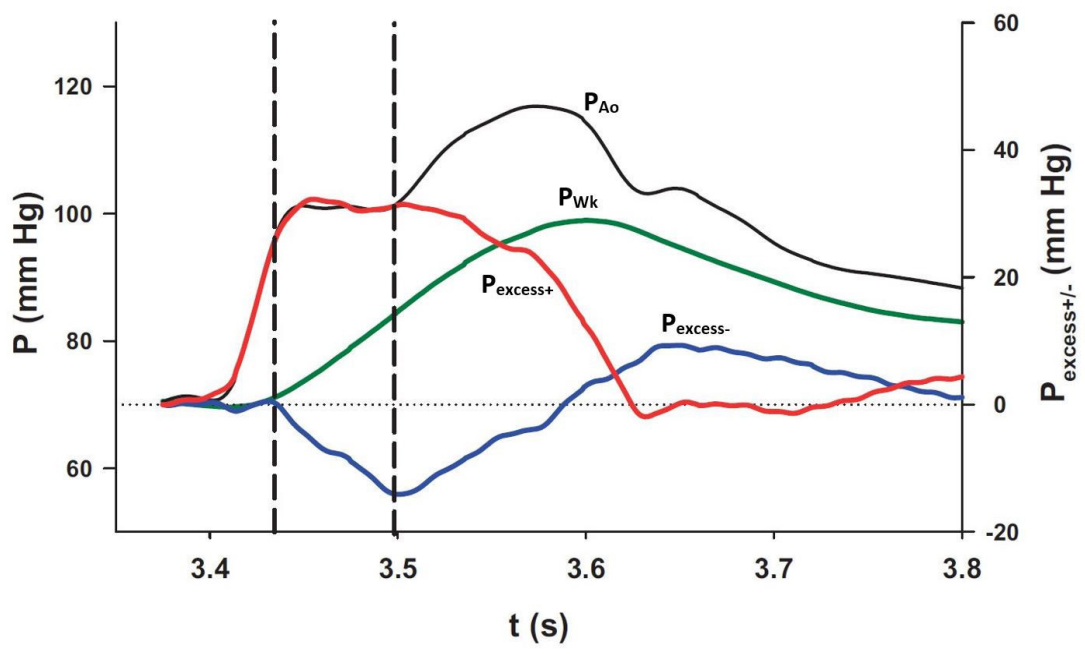

Figure 3. The interaction of each of the pressure components at the diaphragm. $P_{\mathrm{Ao}}$ and $P_{\mathrm{wk}}$ (black and green lines, respectively; scale on the left) were plotted together with $P_{\text {excess }}$ and $P_{\text {excess- }}$ (red and blue lines, respectively; scale on the right). The plateau in measured pressure is delimited by the vertical dashed lines during which interval the increase in $P_{\text {wk }}$ is exactly equalled by the decrease in $P_{\text {exces }}$ [8]

Note. Reprinted with permission from "Wave propagation and reflection in the canine aorta: analysis using a reservoir-wave approach" by Wang JJ, Shrive NG, Parker KH, Hughes AD, Tyberg JV. Can J Cardiol. 2011;27:389. (https://doi.org/10.1016/j. cjca.2010.12.072). (C) Elsevier. 


\section{Wave propagation and reflection in the aorta}

We defined aortic wave propagation and reflection in a series of experiments on anesthetized, open-chest dogs [8]. The atrio-ventricular node was blocked and the hearts were paced from the right ventricle. Aortic pressure was measured with a catheter-tip manometer and aortic flows were measured at 4 locations (just above the aortic valve, just beyond the great vessels, at the diaphragm, and at the bifurcation) with ultrasonic flowmeters. For data recording, the ventilator was stopped at end-expiration for several seconds following which hemodynamic stability was re-established. As illustrated in Figure 4A, pressure was recorded at the aortic valve and then the manometer was pulled back by a $2-\mathrm{cm}$ increment and the measurements repeated. This sequence of maneuvers was repeated until the manometer reached the femoral artery. The data were collated retrospectively and plotted as shown. The onsets of the increases in $P_{\mathrm{Ao}}$ are indicated by black dots.

The result of the subsequent analysis is shown in Figure 4B. $P_{\mathrm{wk}}$ has been subtracted from $P_{\mathrm{Ao}}$ to yield $P_{\text {excess }}$, which was plotted against time and distance. [WIA requires flow (velocity) as well as pressure measurements so WI was calculated only where flow was measured]. WIA defines whether a wave is forwardgoing (i.e., in the direction of net blood flow) or backward-going (i.e., in the direction against net blood flow) and whether it is pressure-increasing (a compression wave) or pressure-decreasing (a decompression wave). Thus, respectively, there are four possibilities: a forward-going compression wave (FCW), a forwardgoing decompression wave (FDW), a backward-going compression wave (BCW), or a backward-going decompression wave (BDW). The FCW followed the course of the black dots in Figure 4A and is indicated by a solid line on the distance-time plane in Figure 4B. As generally anticipated, the FCW proceeded to the femoral circulation where it was reflected positively as a BCW that arrived at the aortic valve after it had closed. (These results in anesthetized animals should not exclude the possibility that the BCW might arrive during systolic ejection and, thus, contribute to systolic hypertension. Pomella et al. [13] have shown recently that wave speed can increase by $\sim 50 \%$ with exercise.) As not so generally anticipated [14], the FCW was also reflected negatively from an abdominal site approximately $40 \mathrm{~cm}$ from the aortic valve; the course of the BDW is depicted by a dashed line. The FDW (not shown) that the LV generates late in ejection and that decelerates the stroke volume was propagated and reflected similarly [8].
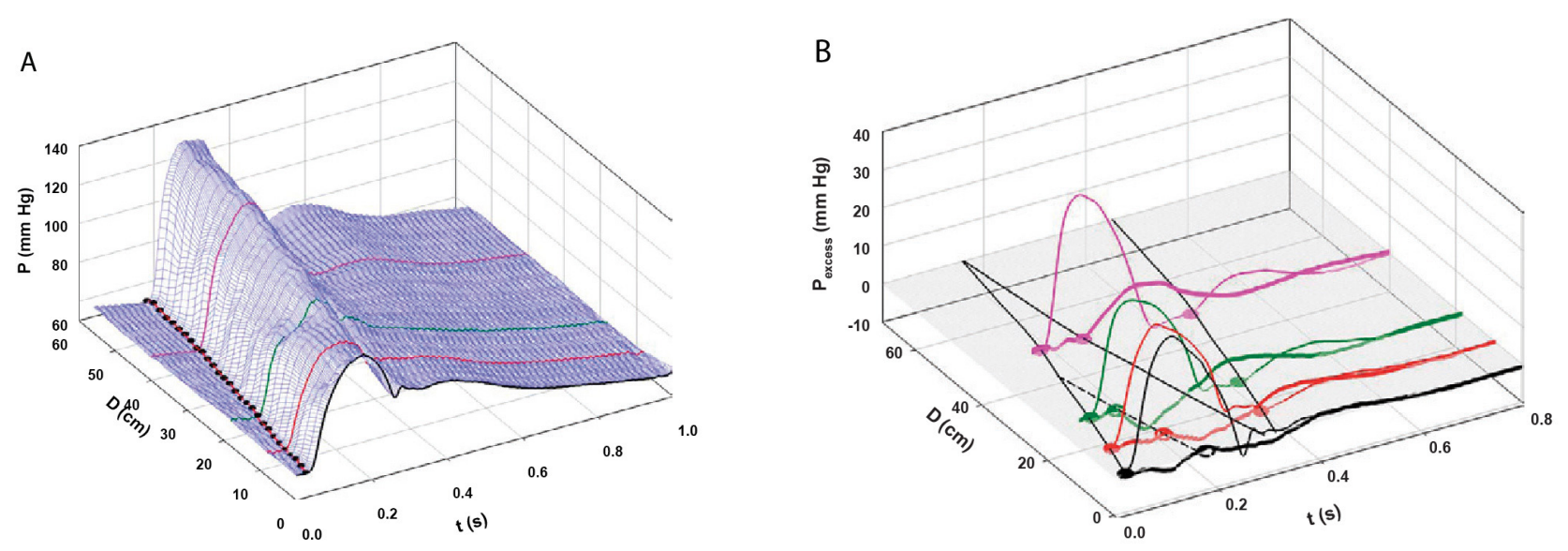

Figure 4. A: Measured aortic pressure $(P)$ during one cardiac cycle, plotted as a function of time (t) and distance (d; from the aortic valve to the femoral artery). Black, red, green, and pink lines indicate the sites at which flows were also recorded (respectively, at the aortic root $(0 \mathrm{~cm})$, just beyond the left subclavian artery $(8 \mathrm{~cm})$, just above the diaphragm $(18 \mathrm{~cm})$, and just above the aortic bifurcation ( $40 \mathrm{~cm}$ from the aortic root). The path of the FCW as a function of time and distance is indicated by black dots; B: pressures due to the passage of forward-going waves ( $P_{\text {excess }} ;$ thin lines) and pressures due to the passage of backward-going waves $\left(P_{\text {excess- }}\right.$; thick lines) were plotted at the locations at which flow was measured. Propagation, distal reflection, and re-reflection and proximal (negative) reflection of the initial FCW are noted in the $P=0$ plane. In this and subsequent figures, compression waves will be indicated by filled circles and solid lines and decompression waves, by open circles and dashed lines [8]

Note. Reprinted with permission from "Wave propagation and reflection in the canine aorta: analysis using a reservoir-wave approach" by Wang JJ, Shrive NG, Parker KH, Hughes AD, Tyberg JV. Can J Cardiol. 2011; 27:389. (https://doi.org/10.1016/j. cjca.2010.12.072). (C) Elsevier.

Parker [4] has provided an explanation for positive and negative reflection based on the ratio of the area of the "daughter" vessels to the "mother vessel". As shown in the left side of Figure 5, significant positive 
reflection $(R>0)$ occurs when the daughter-to-mother-vessel area ratio $(\alpha)$ is less than approximately 0.5 , approaching that of a "closed-end" organ pipe. As shown in the right side, significant negative reflection $(\mathrm{R}<$ 0 ) occurs when the ratio is greater than approximately 2 , approaching that of a "open-end" organ pipe.



Figure 5. Reflection coefficient $(R)$ plotted as a function of the ratio $(\alpha)$ of daughter-vessel total cross-sectional area to mothervessel cross-sectional area. The symmetry ratio is given by $\gamma$ where $Y=0$ corresponds to a straight tube with no bifurcations [4]

We compared this normal pattern of aortic wave propagation and reflection to the alterations effected by vasodilatation [sodium nitroprusside (NP)] infusion and vasoconstriction [methoxamine (Mtx)].

Figures $6 \mathrm{~A}$ and $6 \mathrm{~B}$ show the effects of NP. Notice that the 3-D contour is more complex than that in Figure $4 \mathrm{~A}$ and that the pressure peaks are diminished in some locations by the effects of decompression waves emanating from new sites of negative reflection (in the femoral circulation approximately $50 \mathrm{~cm}$ from the aortic valve and from the aortic arch, approximately $10 \mathrm{~cm}$ from the aortic valve). These new, negatively reflecting sites may be due to the nitrate-induced dilatation of conducting arteries, as was demonstrated previously $[7,15,16]$.
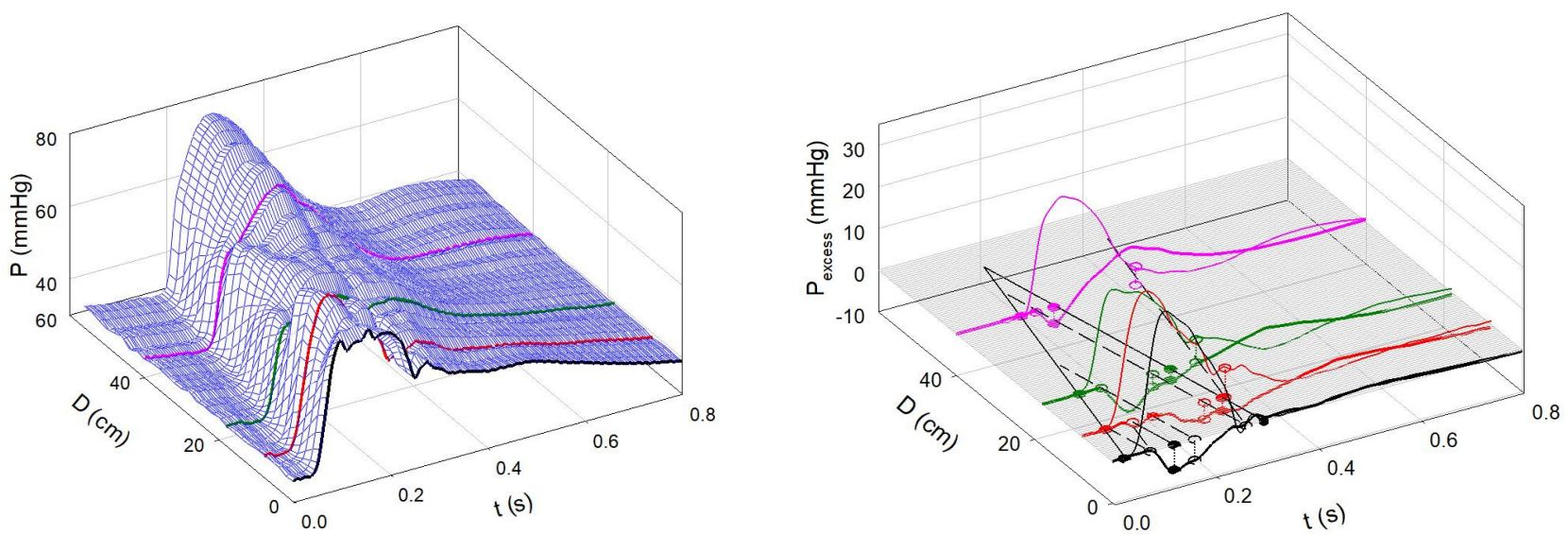

Figure 6. Infusion of NP. A: Measured aortic pressure plotted as a function of time and distance. Note that the contour is less regular than in Figure 4; B: path of the FCW and the reflected backward waves. Waves were reflected negatively from the descending aorta, a sub-diaphragmatic site near the renal arteries, and near the aorto-iliac junction and positively from a femoral artery site [7]

Note. Reprinted with permission from "Alterations in aortic wave reflection with vasodilation and vasoconstriction in anaesthetized dogs" by Wang JJ, Bouwmeester JC, Belenkie I, Shrive NG, Tyberg JV. Can J Cardiol. 2013; 29:243-53. (https://doi.org/10.1016/j. cjca.2012.03.001). (c) Elsevier.

Figures 7A and 7B show the effects of Mtx. Notice that the 3-D contour is less complex than that in Figure $4 \mathrm{~A}$ and that the negative reflection from the abdominal site is absent. Figure 8 shows an example of greatly enhanced wave reflection due to Mtx.

Most importantly, it must be appreciated that these remarkably clear definitions of aortic wave propagation and reflection became possible only because we separated $P_{\mathrm{Ao}}$ into the sum of $P_{\mathrm{wk}}$ and $P_{\text {excess }}{ }^{\circ} P_{\mathrm{wk}}$ 
is the volume-related pressure and $P_{\text {excess }}$ is the wave-related pressure. Our first step was to calculate $P_{\text {wk }}$ and subtract it from $P_{\mathrm{Ao}}$. The distance-time pattern of $P_{\text {excess }}$ defines wave propagation and reflection
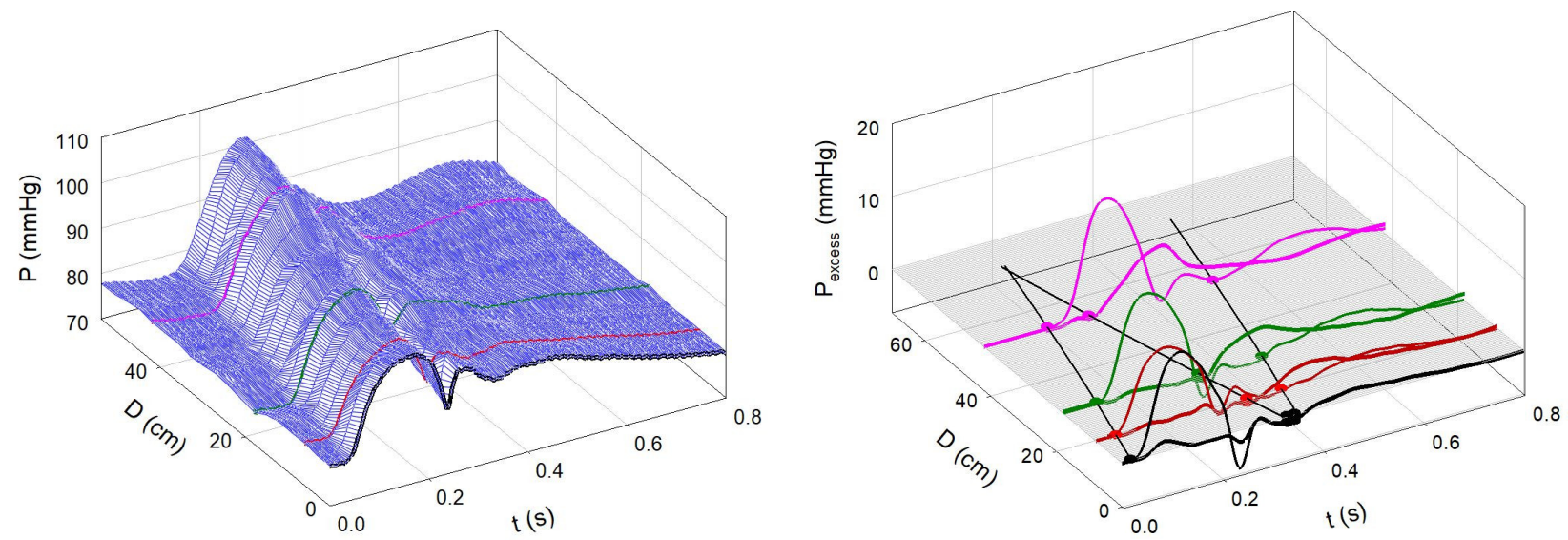

Figure 7. Infusion of Mtx. A: Measured aortic pressure plotted as a function of time and distance. Note that the contour is more regular than in Figure 4; B: path of the FCW and the reflected wave. Note the absence of negative reflection from the abdominal region [7]

Note. Reprinted with permission from "Alterations in aortic wave reflection with vasodilation and vasoconstriction in anaesthetized dogs" by Wang JJ, Bouwmeester JC, Belenkie I, Shrive NG, Tyberg JV. Can J Cardiol. 2013; 29:243-53. (https://doi.org/10.1016/j. cjca.2012.03.001). (C) Elsevier.

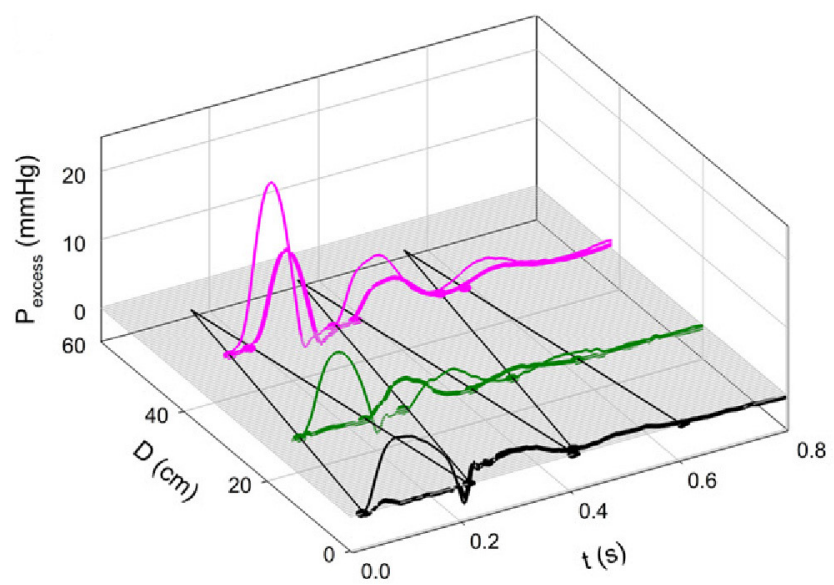

Figure 8. Note the remarkable "billiard-ball" pattern of multiple reflection and re-reflection. The initial FCW was reflected from the periphery, re-reflected from the closed aortic valve, re-re-reflected from the periphery, again re-re-re-reflected from the closed aortic valve, and re-re-re-reflected to cause a BCW above the aortic bifurcation. With Mtx, aortic stiffness and wave speed were increased [7]

Note. Reprinted with permission from "Alterations in aortic wave reflection with vasodilation and vasoconstriction in anaesthetized dogs" by Wang JJ, Bouwmeester JC, Belenkie I, Shrive NG, Tyberg JV. Can J Cardiol. 2013; 29:243-53. (https://doi.org/10.1016/j. cjca.2012.03.001). (C) Elsevier.

When our original paper was assessed for publication a reviewer suggested that we apply Westerhof's concepts [1] to our data at each of the 4 locations, for comparison with our analysis. Figure 9 shows the result. The thinner lines indicate the forward-going wave (Westerhof, $P_{\mathrm{f}}$ ), and the thicker lines, backward pressure wave (Westerhof, $P_{\mathrm{b}}$ ). At each location, note that $P_{\mathrm{b}}$ follows $P_{\mathrm{f}}$ by approximately the same interval, observations that are consistent with those of Davies et al. [17]. In contrast to a forward-going wave, a backward-going wave should occur first in the periphery and only later, in the proximal circulation.

In 2015, Westerhof, Segers, and Westerhof [18] responded to these concerns. With respect to the fact that $P_{\mathrm{b}}$ goes forward, they compared the phenomenon to an "echo in a gallery with many arcades". It is not clear what they think of our observations shown in Figure 9. If they do grant the validity of our observations, we cannot imagine how a gallery with many arcades would create a central $P_{\mathrm{b}}$ waveform that was really propagated backward from the components arising from these peripheral locations. Furthermore, how does a gallery composed of fixed arches respond appropriately to a great range of heart rates? With respect to the "flow waves" during diastole they remained adamant stating "self-cancelling waves are perfectly in line with wave theory because the compound forward and compound backward flow waves cancel when reflecting 
against a closed valve resulting in net zero diastolic flow". However, they do not provide any physical or physiological explanation for either the systolic or diastolic phenomena.

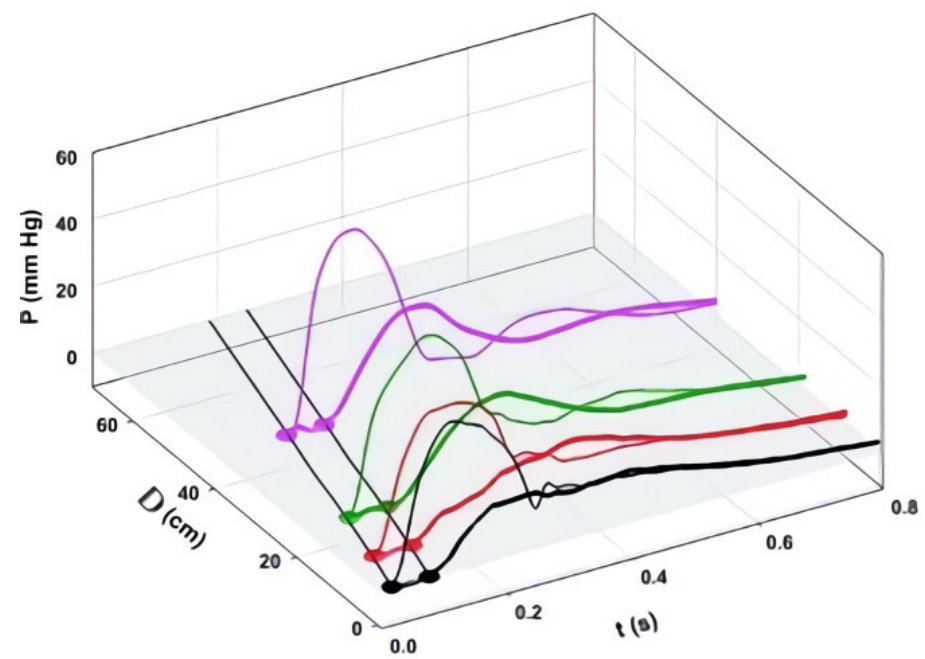

Figure 9. Separation of forward- $\left(P_{\mathrm{f}}\right.$, thin lines) and "backward-going" ( $P_{\mathrm{b}}$, thick lines) pressure waves based on measured pressures and flows, according to the classical method [10]. At every location, note that $P_{\mathrm{b}}$ follows $P_{\mathrm{f}}$ by approximately the same interval [8]

Note. Reprinted with permission from "Wave propagation and reflection in the canine aorta: analysis using a reservoir-wave approach" by Wang JJ, Shrive NG, Parker KH, Hughes AD, Tyberg JV. Can J Cardiol. 2011; 27:389. (https://doi.org/10.1016/j. cjca.2010.12.072). (C) Elsevier.

As indicated at the outset, Westerhof et al. [10] assumed that all the variation in aortic pressure and flow could be explained completely by the summation of the effects of forward- and backward-going waves. While this conceptual framework has been almost universally accepted for five decades, it led to two difficult-toexplain implications: during systole, it implied "backward waves" that are forward-going and, during diastole, it implied opposite and self-cancelling flow waves, the physical source of which has never been explained. Given these profound conceptual difficulties, we suggested that some of the change in pressure could be due a change in the volume of the proximal aorta, Frank's Windkessel mechanism [6].

How can a forward-going backward wave be explained? In the ascending aorta and throughout the arterial circulation local flow reaches its peak while local pressure is still increasing. If only forward and backward waves are involved, the logic is simple: it must be caused by a backward-going, pressure-increasing wave. This seemed to be an acceptable explanation until we performed the classical analysis on each data set at 4 different locations, which demonstrated that the "backward" wave was propagated forward. These phenomena are illustrated in Figure 10. Note that the onsets of the $P_{\mathrm{b}}$ 's (thicker lines) occur precisely simultaneously with the peaks of the local flow contours (interrupted thick lines).

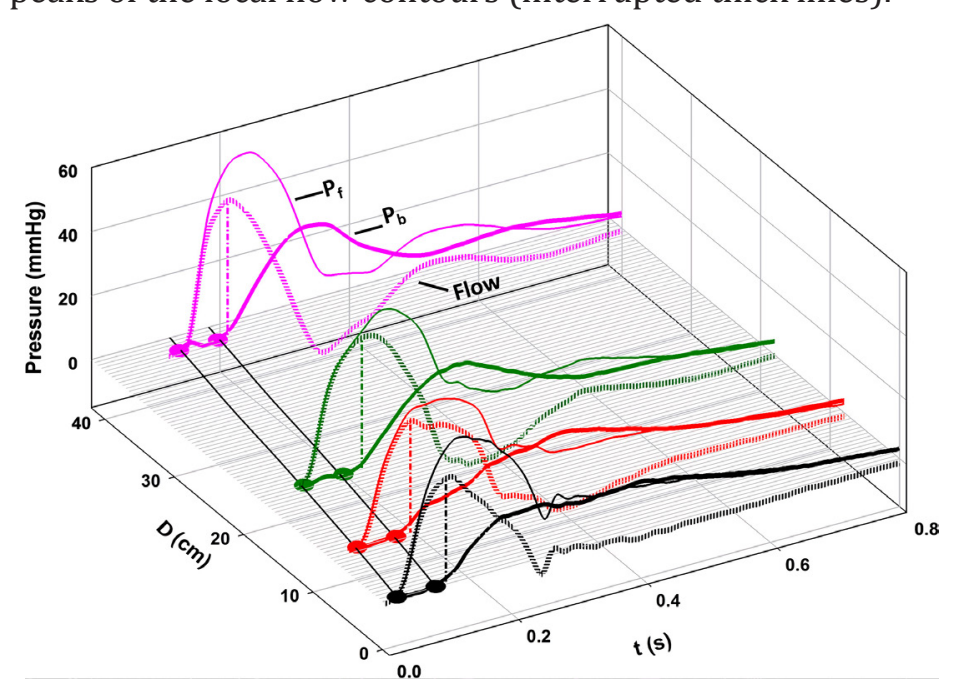

Figure 10. Comparison of the beginning of the $P_{\mathrm{b}}$ waveform at each location to the time of the peak of the waveform (interrupted thick lines). Because the magnitudes of flow at each location were so different, they have been scaled arbitrarily to facilitate comparison (the flow at the aortic root was divided by 5 ; flows at just beyond the subclavian artery and at the diaphragm 
were divided by 2.5 ; and the flow at the bifurcation was multiplied by 1.5$)$. Notice that the $P_{\mathrm{b}}$ waveform begins when flow begins to decrease at each location [19]

Note. Reprinted with permission from "Origin of the forward-going 'backward' wave" by Tyberg JV, Burrowes LM, Shrive NG, Wang JJ. J Appl Physiol. 2017;123:1406-7. (https://doi.org/10.1152/japplphysiol.00350.2017). @ The American Physiological Society.

\section{Conclusions}

Considering the effects of Frank's Windkessel enables precise definition of wave propagation and reflection as demonstrated here. Furthermore, it eliminates the logically troublesome implications of the wave-only explanation of aortic pressure and flow variation: the forward-going "backward" wave and equal and opposite diastolic flow waves that were never explained mechanistically and that served only to satisfy the numerical constraints imposed by decreasing diastolic aortic pressure in the absence of flow.

\section{Abbreviations}

BCW: backward-going compression wave

FCW: forward-going compression wave

LV: left ventricle

Mtx: methoxamine

NP: sodium nitroprusside

$P$ : pressure

$P_{\infty}$ : asymptotic pressure

$P_{\mathrm{Ao}}$ : aortic pressure

$P_{\mathrm{b}}$ : backward pressure wave (Westerhof)

$P_{\text {excess- }}$ : backward-going waves excess pressure

$P_{\text {excess }}:$ excess pressure

$P_{\text {excess }}:$ forward-going waves excess pressure

$P_{\mathrm{f}}$ forward pressure wave (Westerhof)

$P_{\text {wk }}:$ Windkessel pressure

$Q_{\text {in: }}$ aortic inflow

$U$ : velocity

WI: wave intensity

WIA: wave intensity analysis

\section{Declarations}

\section{Acknowledgements}

Dr. Tyberg acknowledges the substantial help of Dr. Maryell Urroz Lopez in the preparation of the manuscript, the critical scientific contributions of Drs. Jiun-Jr Wang and Nigel Shrive, and the great surgical skill and assiduous attention to quality demonstrated by Cheryl Hall with respect to all the experiments upon which this paper is based.

\section{Author contributions}

The author contributed solely to the work.

\section{Conflicts of interest}

The author declares that he has no conflicts of interest.

\section{Ethical approval}

Not applicable. 


\section{Consent to participate}

Not applicable.

\section{Consent to publication}

Not applicable.

\section{Availability of data and materials}

Not applicable.

\section{Funding}

Not applicable.

\section{Copyright}

(c) The Author(s) 2021.

\section{References}

1. Westerhof N, Sipkema P, van den Bos GC, Elzinga G. Forward and backward waves in the arterial system. Cardiovasc Res. 1972;6:648-56.

2. Wang JJ, Shrive NG, Parker KH, Tyberg JV. "Wave" as defined by wave intensity analysis. Med Biol Eng Comput. 2009;47:189-95.

3. Lighthill J. Waves in fluids. 1st ed. Cambridge: Cambridge University Press;1978. p.106.

4. Parker KH. An introduction to wave intensity analysis. Med Biol Eng Comput. 2009;47:175-88.

5. Wang JJ, O'Brien AB, Shrive NG, Parker KH, Tyberg JV. Time-domain representation of ventricular-arterial coupling as a windkessel and wave system. Am J Physiol Heart Circ Physiol. 2003;284:H1358-68.

6. Frank O. Die Theorie der Pulswellen. Z Biol. 1926;85:91-130.

7. Wang JJ, Bouwmeester JC, Belenkie I, Shrive NG, Tyberg JV. Alterations in aortic wave reflection with vasodilation and vasoconstriction in anaesthetized dogs. Can J Cardiol. 2013;29:243-53.

8. Wang JJ, Shrive NG, Parker KH, Hughes AD, Tyberg JV. Wave propagation and reflection in the canine aorta: analysis using a reservoir-wave approach. Can J Cardiol. 2011;27:389

9. Parker KH, Alastruey J, Stan G-B. Arterial reservoir-excess pressure and ventricular work. Med Biol Eng Comput. 2012;50:419-24

10. Westerhof N, Bosman F, De Vries CJ, Noordergraaf A. Analog studies of the human systemic arterial tree. J Biomech. 1969;2:121-43.

11. Tyberg JV, Shrive NG, Bouwmeester JC, Parker KH, Wang Jr J. The reservoir-wave paradigm: potential implications for hypertension. Curr Hypertens 2008;4:203-13.

12. Tyberg JV, Bouwmeester JC, Parker KH, Shrive NG, Wang JJ. The case for the reservoir-wave approach. Int J Cardiol. 2014;172:299-306.

13. Pomella N, Wilhelm EN, Kolyva C, González-Alonso J, Rakobowchuk M, Khir AW. Noninvasive assessment of the common carotid artery hemodynamics with increasing exercise work rate using wave intensity analysis. Am J Physiol Heart Circ Physiol. 2018;315:H233-41.

14. Alexander RS. The genesis of the aortic standing wave. Circ Res. 1953;1:145-51.

15. Fitchett DH, Simkus GJ, Beaudry JP, Marpole DG. Reflected pressure waves in the ascending aorta: effect of glyceryl trinitrate. Cardiovasc Res. 1988;22:494-500.

16. Yaginuma T, Avolio A, O'rourke M, Nichols W, Morgan JJ, Roy P, et al. Effect of glyceryl trinitrate on peripheral arteries alters left ventricular hydraulic load in man. Cardiovasc Res. 1986;20:153-60. 
17. Davies JE, Alastruey J, Francis DP, Hadjiloizou N, Whinnett ZI, Manisty CH, et al. Attenuation of wave reflection by wave entrapment creates a "horizon effect" in the human aorta. Hypertension. 2012;60:778-85.

18. Westerhof N, Segers P, Westerhof BE. Wave separation, wave intensity, the reservoir-wave concept, and the instantaneous wave-free ratio: presumptions and principles. Hypertension. 2015;66:93-8.

19. Tyberg JV, Burrowes LM, Shrive NG, Wang JJ. Origin of the forward-going "backward” wave. J Appl Physiol. 2017;123:1406-7. 